\title{
AN IMPROVEMENT OF A CELLULAR MANUFACTURING SYSTEM DESIGN USING SIMULATION ANALYSIS
}

\author{
Hachicha, W. ; Masmoudi, F., ${ }^{* * *} \&$ Haddar, M. ${ }^{*, * *}$ \\ *Unit of Mechanics, Modelling and Production (U2MP), B.P. W, 3038 Sfax, Tunisia \\ ${ }^{* *}$ Department of Mechanical Engineering, Engineering School of Sfax, B.P. W, 3038 Sfax, Tunisia \\ E-Mail: faouzi.masmoudi@enis.rnu.tn
}

\begin{abstract}
Cell Formation (CF) problem involves grouping the parts into part families and machines into manufacturing cells, so that parts with similar processing requirements are manufactured within the same cell. Many researches have suggested methods for CF. Few of these methods; have addressed the possible existence of exceptional elements (EE) in the solution and the effect of correspondent intercellular movement, which cause lack of segregation among the cells. This paper presents a simulation-based methodology, which takes into consideration the stochastic aspect in the cellular manufacturing (CM) system, to create better cell configurations. An initial solution is developed using any of the numerous CF procedures. The objective of the proposed method which provides performances ratings and cost-effective consist in determine how best to deal with the remaining EE. It considers and compares two strategies (1) permitting intercellular transfer and (2) exceptional machine duplication. The process is demonstrated with a numerical example.

(Received in February 2007, accepted in August 2007. This paper was with the authors 2 months for 1 revision.)
\end{abstract}

Key Words: Cell Formation, Exceptional Elements, Simulation, Alternative Costs, Improvement

\section{INTRODUCTION}

The manufacturing sector has become increasingly competitive, as markets have become more globalized. Producers of goods are under intense pressure to improve their operations by enhancing productivity, quality, customer responsiveness, and reducing manufacturing costs. Consequently, there have been major shifts in the design of manufacturing systems using innovative concepts. The adoption of Group Technology (GT) has consistently formed a central element of many of these efforts and has received considerable interest from both practitioners and academicians.

GT is an approach to manufacturing and engineering management that helps manage diversity by capitalizing on underlying similarities in products and activities. Within the manufacturing context, GT is by definition, a manufacturing philosophy identifying similar parts and grouping them together into families to take advantage of their similarities in manufacturing and design. One application of the GT philosophy is cellular manufacturing (CM).

CM has emerged in the last two decades as an innovative manufacturing strategy that collects the advantages of both product and process oriented systems for a high variety and medium volume product mix [1]. In a CM system, functionally diverse machines are grouped in cells, each of which is dedicated to the production of a part family, composed of different parts with similar processing requirements. One important advantage of CM is that production control is considerably simplified and a more realistic delivery quotation can be given to 
customers. That is because of the possibility of more accurately forecasting the time by which finished products will be dispatched after the job has been issued to the works.

One of the crucial steps in the design of a CM system is the Cell Formation (CF) problem. The CF problem consists in grouping machines into cells and in determining part families such that parts of a family are entirely processed in one cell. Unfortunately, it is not always possible to ensure that a part is treated in one cell, because a machine of a cell may be required by parts from different families. Such parts or machines are called exceptional elements and are to be minimized when assigning parts and machines to cells [2,3]. An exceptional machine which also called bottleneck machines processes parts from two or more part families. An exceptional part can be viewed as parts that require processing on machines in two or more cells. As will be discussed later, this interaction creates disruptions in CM environment.

Extensive work has been performed in the area of CF problem and numerous methods have been developed. The main used techniques are classification and coding systems, machine-component group analysis, mathematical and heuristic approaches, similarity coefficient based on clustering methods, graph-theoretic, knowledge-based and pattern recognition methods, fuzzy clustering methods, correlation analysis approaches, evolutionary and neural network approaches. Therefore, theses numerous methods can be also classified into binary data based and production information. The binary data based problems consider only assignment information, that is, a part needs or needs not a machine to perform an operation. The assignment information is usually given in $0-1$ incidence matrix (e. g in [4], [5], [6] and others). The binary data based problems consider only a single objective in identifying cells. This ignores the fact that the CF problem, by structure, contains multiples objectives and limitations. In general, these only focus on the single objective of cell independence, which could make the final configuration unsuitable for implementation since factors such as machines loadings and utilization [7, 8]. To overcome these limitations, the production information based problems is based on the idea that necessary production data (such as production volumes, operation times, operation sequences, and others) should be incorporated in the early stages of the machine component grouping process (e. g in [7], [9], [10] and others). The performance guarantee of these methods is not know. The limited number of comparisons published to date indicates that solution differ depending upon the algorithm used [8]. Thus, there is a vital need for using simulation study. On the one hand, to justify and to validate principally the final CF design and on the other hand, to screen indirectly the applicability of the vast varieties of techniques which proposed in literature.

The existence of EE in a CM system which results in intercell transfers let the CF design more complicated. Some parts will have routeings that take them outside of their part family's cell, increasing the likelihood of confusion in the scheduling and control of the involved cells $[11,12]$. Some organizations opt to duplicate machines in different cells in an effort to eliminate intercell transfers. Others eliminate exceptional parts by subcontracting, redesigning the part, or adopting special routeings. It is often important in practice to be able to reassign parts to additional machine types. This involves extending the set of parts that certain individual machines can process. Such extensions may be economically better than simply purchasing additional machines. Thus, there is the possibility of machine modification to reduce intercell travel. These actions may have an effect on more than one element in CM structure; there is a great interdependency among the elements. Whether the organization accepts the existence of intercell transfers, or attempts to eliminate them, a cost is incurred which needs to be minimized.

This paper presents a simulation-based methodology for identifying opportunities for reducing the number of intercell transfers after an initial CF solution has been obtained, regardless of the approach taken to create the initial solution. CF is first completed and known 
as a prior, i.e. what kinds of machines and parts belong to which cells are known. The proposed approach suggests whether it is cost-effective and performances ratings to eliminate an EE by machine duplication or whether the intercellular transfers caused by EE should remain in the CF. It provides an improvement in the initial CF solution.

The outline of the paper is as follows. Section 2 presents two brief literature reviews. The first concerns the methods to eliminating EE in CF solution. The second consists on the use of simulation study in CM systems. Then the problem description and the corresponding simulation model are shown in section 3 and section 4, respectively. Afterwards, section 5 presents the obtained results and analysis. Lastly, conclusion is made in Section 6.

\section{LITERATURE REVIEW}

The aim of this paper is to propose a simulation-based methodology to improve a CM system and consequently to create a better cell configurations. That is why the remainder of this literature review subsection is organized as follows. First, a summary literature review of the eliminating EE is presented. Secondly, literatures review of using simulation in the design and the analysis of CM systems.

\subsection{Eliminating EE}

Many authors have suggested methods and algorithms for CF problem. Wemmerlöv and Hyer [12] provide a comprehensive review of the literature where they indicate that it is extremely rare to find completely independent cells. For the purposes of this work, it is interesting to note the variety of approaches that researchers have adopted in addressing the existence of EE. As will be seen, in most cases the authors of these algorithms either eliminate the EE from consideration, completely or they temporarily remove them from the problem and reinstate them on conclusion of the process, or they do not deal with $\mathrm{EE}$ at all.

McAuley [13] is the first who incorporated the EE elimination into CF solution. He assumed that bottleneck machines would be duplicated to eliminate intercell transfers. The problem with this approach is the preclusion of others strategies for eliminating the need for intercell transfers. The duplication of bottleneck machines may not be the cost-effective alternative. King [14] and Chan and Milner [5] temporarily ignore EE by duplicating machines. The EE are then reinstated in the solution generated by their algorithm, and the duplicate machines are removed. Chan and Milner [5], Burbidge [15], and others describe four alternatives for eliminating $\mathrm{EE}$ and consequently create better cell configurations, including: rerouting or redesigning the component, duplicating machines or bottleneck machine duplication. This action would eliminate the need for transferring parts between cells in order for them to receive processing on bottleneck machines, forming an independent cluster of EE (sometimes called the 'remainder cell'), or finally, permitting the intercell transfers.

Kusiak [16] proposes another alternative to eliminate EE which consist in subcontracting the component (the exceptional parts) i.e. removing it from the CM production environment. He used subcontracting costs as a means of evaluating the EE that exist in CF solutions that he generated. In some cases, subcontracting is a viable alternative to the duplication of bottleneck machines. Seifoddini [17] presents examples where cell-clustering algorithms based upon similarity coefficients results in inappropriate solutions. He maintains that the solutions are inappropriate because they do not attempt to minimize the number of intercell transfers. Shafer, Kern and Wei [11] proposes a mathematical optimization model to determine how best to deal with the remaining $\mathrm{EE}$ and to compares between machine duplication action and exceptional parts subcontracting action. 
It has been noted by Burbidge [1], Wemmerlov and Hyer [12], Selim et al. [8] and recently by Foulds et al. [18] that it is often important in practice to be able to reassign parts to different machine types in order to create better cell system configurations. This involves extending the set of parts that certain individual machines can process. Such extensions may be cheaper than simply purchasing additional machines. Thus, there is the possibility in CF system, of machine modification to reduce inter-cell travel. When such machine modification is feasible, the resulting CF problem is called "the sustainable cell formation problem". This problem is not considered in the present study.

Most of these mentioned papers use an exact or an approximate mathematical programming method (e.g in [11], [17]) to solve the above EE eliminating problem. Recently, Cheng et al. [19] proposed a heuristic branching rules to allocate EE in the final CF solution. Hachicha et al. [6] suggested also the use of a correlation analysis approach to assign EE to the final CF solution. The configuration of each cell in the given solution stays the same unless it is changed by actions taken for EE elimination such as machine duplication. Due to the complex and interdependent nature of this problem (determine how best to deal with the remaining EE), significant manufacturing information such as processing time, Setup time, production volume, sequence and alternative routings must be integrates in the early stages of grouping decisions for CM and of EE eliminating.

To achieve the objective, there are three basic types of models which are available for the analysis of manufacturing cells. These types are static (deterministic) models, queuing models and computer simulation models. As far we are aware, in general manufacturing system science, computer simulation is arguably the most powerful of the three techniques. Compared to the other types of models, dynamic system characteristics may be incorporated into the model relatively easily; so that a high degree of realism can be achieved.

\subsection{Simulation studies}

Simulation models and spatially discrete-event simulation can provide increased comprehension of, and improved insight into, the performance of a manufacturing system. The very act of constructing the simulation model forces the modeler to ask the questions which foster this insight. Analysis of the numerical results of the simulation runs can be used to identify true performance indicators for the system such as total time in the system for a part, work-in-process inventory, and machine utilization for making.

Simulation is widely used in the world and therefore it is very familiar ([20], [21], [22] and other). The most important reasons and advantages of simulation methodology for modelling manufacturing systems are that [21]:

- realistic models are possible, they are a practical approach to representing the important characteristics of a manufacturing system and may incorporate any complex interactions that exist between different variables;

- options may be considered without direct system experimentation and alternative designs can be easily evaluated, independently of the real system;

- a computer simulation models ability to directly address the performance measures typically used in a real system;

- non-existent systems may be modelled;

- visual output helps and assists the end-user in model development and validation;

- no advanced mathematics is required;

- analytical methods are perceived to be unhelpful by management or may require oversimplification.

Scientists and industrial managers rightfully recognise the use of simulation for CF systems design and analysis and the literature is abundant in this field. We can refer to several subjects such as: 
- manufacturing cell sizing such as number of duplicates of each type of machine in the cell, queue sizes, and others design parameters (e.g in [20], [22]);

- comparison of functional, cellular and hybrid layouts (e.g in [23], [24], [25]);

- productivity analysis (e.g in [26], [27], [30]);

- impacts of factors which influencing the CM and potential problems that may arise (such as machine tool wear-out, breakdowns, and so on) as well as other cell configuration parameters and the factors that affect them (e.g in [28]); and

- others.

Most of mentioned CM simulation studies have indicated the importance of workload balancing and machine utilization in determining the advantage of cells. However, many of the better known CF techniques and EE eliminating do not include machine utilization nor consider multiple machines of the same type. The proposed simulation methodology which is described in the next subsection extended and embedded in larger solution schemes that will include such considerations.

\section{PROBLEM DESCRIPTION}

The system investigated and modelled is a production shop consisting of three manufacturing cells (labeled C1-C3). These cells support the production of three part families, for a total of 10 separate part types (labeled P1-P10). The cells are automated, with intracellular material handling accomplished by means of an automated material handling system integrated with each machine. Nine different machines (labeled M1-M9) comprise the three cells. Cell C1 consists of machines $1-3$ and processes parts $1-3$. Cell C2 consists of machines $4-5$ and processes parts 4-6. Cell C3 consists of machines 6-9 and processes parts 7-10.

Shafer, Kern and Wei [11] provide the same example. Their original problem has been revised and slightly modified to include production data such as sequence for each part and setup time. For the purpose of the example, it is further assumed that none of the eight exceptional elements can be eliminated by modifying the processing requirements or design of the parts. It is also assumed that each machine capacity is enough to process completely all parts volume.

In this paper, we employ the following notation:

$i \quad$ - index sets for parts: $i=1,2,3 \ldots 10$

$j \quad$ - index sets for machines: $j=1,2,3 \ldots 9$

$B S_{i} \quad$ - batch size for part $i$

$D_{i} \quad$ - annual forecasted demand for a batch of part $i$,

$p_{i} \quad$ - proportion of batch demand for part $i$.

$N T_{i} \quad$ - number of intercell transfers for part $i$

$T T_{i} \quad$ - intercellular time transfers for a batch of part $i$

$I C_{i} \quad$ - incremental cost for moving part $i$ outside of a cell as opposed to moving it within the cell

$A_{j} \quad$ - annual cost of acquiring a machine of type $j$

Table I shows the investigated system data. At the top of Table I, the machine part matrix is presented. Information on the processing time each part requires (in minutes) is given instead of simply showing machines each part requires. We assume that it is an initial CF solution, which is developed using any of the numerous CF procedures. The last row in Table I contain the unit intercellular transfer cost for each batch of parts. The last columns contain the acquisition cost of each machine per year. 
Table I: System investigated data.

\begin{tabular}{|c|c|c|c|c|c|c|c|c|c|c|c|}
\hline & P1 & P2 & P3 & P4 & P5 & P6 & P7 & P8 & P9 & P10 & $A_{j}(\$)$ \\
\hline M1 & 2.95 & & 2.20 & & & & & & & 4.61 & 10000 \\
\hline M2 & 2.76 & 5.18 & 1.89 & 3.89 & & 5.14 & & & & & 10000 \\
\hline M3 & 5.54 & 4.29 & & & & & & & & & 10000 \\
\hline M4 & 2.91 & & & 1.97 & 2.59 & 4.01 & & 2.7 & & & 10000 \\
\hline M5 & & & & 4.28 & & 4.51 & & & & & 10000 \\
\hline M6 & 1.92 & & & & & & 2.23 & & 5.52 & & 10000 \\
\hline M7 & & & & & 3.4 & & 1.16 & 4.72 & & 2.49 & 10000 \\
\hline M8 & & 5.32 & & & & & & 3.75 & 3.85 & & 10000 \\
\hline M9 & & & & & & & 4.04 & & & 1.83 & 10000 \\
\hline$I C_{i}(\$)$ & 6.8 & 7.5 & 5.8 & 5.4 & 6.5 & 6.5 & 4.5 & 6.2 & 5.1 & 6.8 & \\
\hline
\end{tabular}

We assume that each part has a unique sequence that indicated in Table II. Each part is assigned to one cell. If a process plan contains a machine, which is assigned to another cell, then an intercell movement is considered ( $T T_{i}$ in minutes). Further $\mathrm{CM}$ system considerations are described as follows: parts are moved in batches between cells and inside cells. The time of intercell per batch is known and equal to $T T_{i}$. The intra-cell movements are assumed of course to 0 .

Table II: Processing and transfer information.

\begin{tabular}{|c|l|c|c|c|c|c|}
\hline Parts & Processing sequence & $T T_{i}$ & $B S_{i}$ & $D_{i}$ & $p_{i}$ & $N T_{i}$ \\
\hline P1 & M1-M2-M4-M3-M6 & 21 & 5 & 2439 & 0.08 & 3 \\
\hline P2 & M2-M3-M8 & 21.5 & 5 & 4189 & 0.15 & 1 \\
\hline P3 & M2-M1 & 17.5 & 5 & 3135 & 0.11 & 0 \\
\hline P4 & M4-M5-M2 & 22 & 5 & 861 & 0.03 & 1 \\
\hline P5 & M4-M7 & 25 & 5 & 2808 & 0.10 & 1 \\
\hline P6 & M4-M2-M5 & 19.5 & 5 & 2587 & 0.09 & 2 \\
\hline P7 & M6-M7-M9 & 22 & 5 & 3506 & 0.12 & 0 \\
\hline P8 & M4-M7-M8 & 23 & 5 & 3445 & 0.12 & 1 \\
\hline P9 & M6-M8 & 25 & 5 & 2491 & 0.09 & 0 \\
\hline P10 & M7-M9-M10 & 25 & 5 & 3339 & 0.11 & 1 \\
\hline & & & 28800 & 1.00 & 10 \\
\hline
\end{tabular}

Note that the number of intercell transfers is not only determined by the number of EE, but also by the part's sequence or routeing. An intermediate operation for a part performed outside the cell will necessitate two intercell transfers (one out and one to return) such as in sequence for part 1 and for part 6, while only one transfer is needed if the external operation is the first or last of the part's routeing such as part 2, part 4, and others. Consequently, the total number of EE in the system is eight; on the contrary, the total number of intercell transfers is ten.

The impact of batch size $\left(B S_{i}\right)$ on system performance has been understood and emphasized in the literature, through [23], [24] and [29]. The former study pointed out that there is an optimal lot size at which flow time and work-in-process inventory are minimized. 
This study considers batch size as a parameter system which is fixed by the designer that why we employ a constant batch size values for each part type.

We assume that parts have known and fixed demand at the beginning of the planning period. The cell produces parts types in random sequence, each part type is produced in proportion $\left(p_{i}\right)$ which given in Eq. (1) to its share of overall demand which is given in Table II. Jobs were generated with a mean inter-arrival time that equalled the batch size divided by the annual forecasted demand.

$$
p_{i}=\frac{D_{i}}{\sum_{k=1}^{10} D_{k}}
$$

Table III presents the setup time, which is allocated by cell type, and consequently machine groups. That is, if two consecutive batches of different parts that were processed at a machine did not belong to the same cell, the later batch incurred setup time. If succeeding batches belonged to the same original cell, no setup time was incurred for the later batch.

Table III: Setup Time.

\begin{tabular}{|c|l|c|c|}
\hline Cell & \multicolumn{1}{|c|}{ Part families } & Machine groups & Setup Time (min) \\
\hline 1 & P1, P2 and P3 & M1, M2 and M3 & 3.5 \\
\hline 2 & P4, P5 and P6 & M4 and M5 & 3.0 \\
\hline 3 & P7, P8, P9 and P10 & M6, M7, M8 and M9 & 4.5 \\
\hline
\end{tabular}

\section{SIMULATION MODEL}

\subsection{Model construction}

We assume that machines capacities are enough to process all forecasted demand. The interarrival demand law is an exponential with respect proportion $p_{i}$ of each part into account. Further considerations incorporated in the model used in this research are as follows:

- All processing times indicated in Table I are deterministic.

- Each intercellular transfer movement of a batch of part $i$ will have durations that are exponentially distributed, each with a mean of $T T_{i}$ as presented in Table II.

- Queue capacities for processing machines are set at 100 parts.

- Parts are removed in batches from queues for processing according to the first-in-first-out rule.

- When batch parts of an intercell movement arrive to the queues serving processing machines, they will instead be placed at the end of the queue according to the first-in firstout scheduling rule.

- A warm-up period is incorporated into every simulation run. The warm-up period will be of 30.000 minutes duration. This value was determined by observing the behaviour of several random variables and choosing the time at which those values reached steady state [29], [30].

The SIMAN / Arena simulation language was used to develop the simulation model of the manufacturing cell. Fig. 1 shows a modelling of this system by the simulation software Arena [31], [32]. The main portion of the model's operation will consist of logic modules to represent parts arrivals, cells, and parts departures. For instance, the module "Create 1" ensures the entry of the product batches within the system. Then each batch is assigned a set 
of attributes such as part type and sequence routing, via le module "Assign 1" Additionally, as the part proceeds through the cell, different attributes record the time delays associated with material handling, processing, intercell transfer. The module "Decide 1" allows parts to the corresponding cell type. Each part families are assigned to the corresponding cell via modules "Assign 2", "Assign 3" and "Assign 4". Then, it is ready to send parts on its way to the first "Enter station" in its corresponding cell (1, 2, or 3). The Enter module transfers an entity to a specified machine station, or the next station in the station visitation sequence defined for the entity. The intercellular transfer time is entered for each part sequence as a route time. Now that have the arriving batches of parts being routed according to their assigned part sequences, a part arrives to the cell, queues for a machine, is processed by the machine, and sent to its next step in the part sequence. All cells can be modeled by a set of machines, which each one is modeled using the "Enter-Process-Leave" module sequence. Finally, the batches leave the system through the module "Dispose 1".

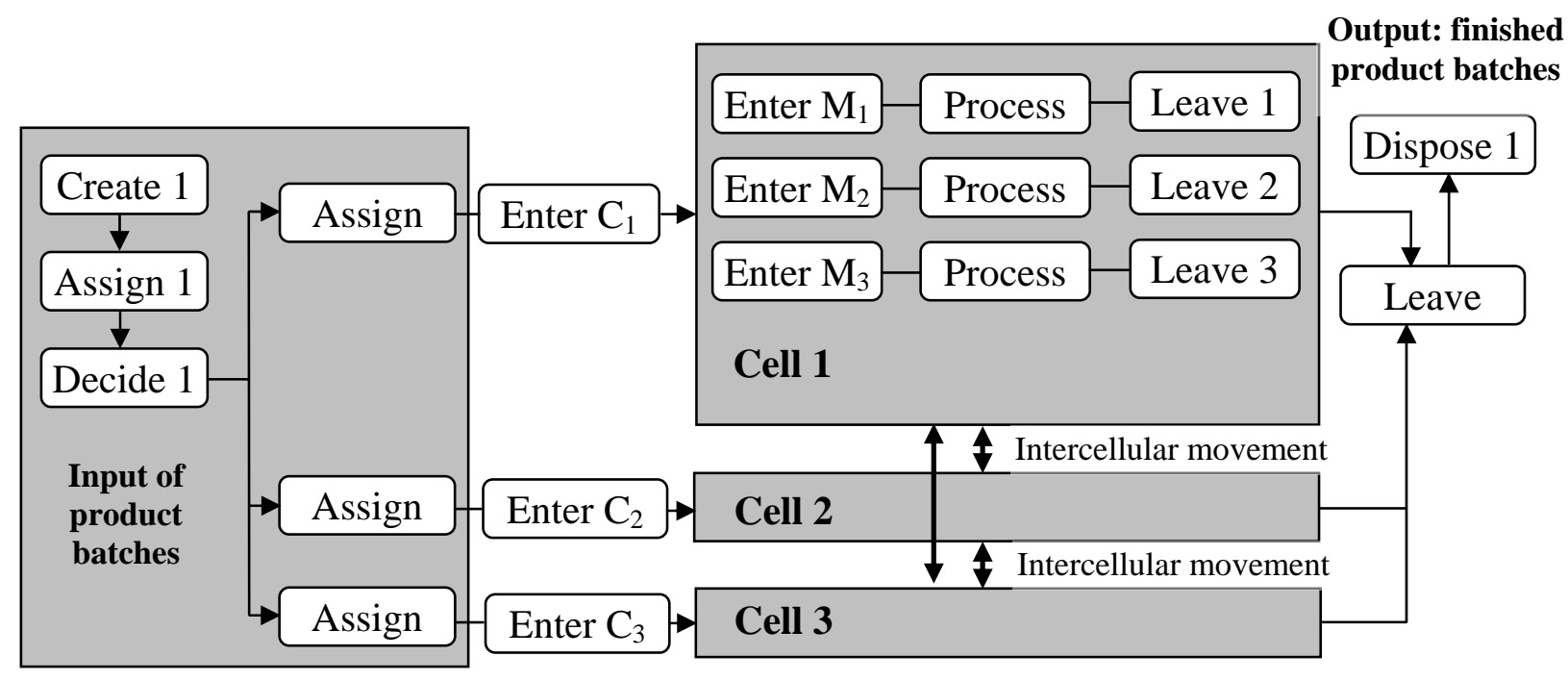

Figure 1: Modeling the investigated system by Arena.

\subsection{Performance measures}

Many performance measures have been employed extensively in the CM performance literature such as in Ref. [20], [21], [22], [25], [30] and others. In this study, which evaluate the effect of transfer time in CM system four performance measures were employed. Theses performance measures included for each part $i$, mean transfer time $\left(M T T_{i}\right)$, mean machining time $\left(M M T_{i}\right)$, mean wait time $\left(M W T_{i}\right)$ and mean flow time $\left(M F T_{i}\right)$. The cost of transfer movement $\left(C T_{i}\right)$ for each part can be determined by applying Eq. (2).

$$
C T_{i}=D_{i} \cdot M T T_{i} \cdot I C_{i}
$$

where $M T T_{i}$ is the mean transfer time; $D_{i}$ is the annual forecasted demand for a batch of part $i$; and $I C_{i}$ is the incremental cost for moving part $i$ outside of a cell as opposed to moving it within the cell. It can also reflect the disruptive effects of having intercellular transfers. Moreover, other performance measures are crucial for the validation of the machine representing is a potential bottleneck or not. It are the average number of batches waiting in machine queue $\left(N W_{j}\right)$ and machine utilization rate $\left(R U_{j}\right)$ should be calculated in order to make sure it is bounded by a higher limit expressing the average machine availability and a lower limit depending on its acquisition cost. 


\section{SIMULATION RESULTS AND ANALYSIS}

We focus our attention on the remaining unchangeable parts routing and on the sufficient machines capacity in each manufacturing cell. The purpose of our procedure consists firstly in evaluation of inter-cellular movements costs using the initial model which permits the intercell transfers for all parts. Second purpose is in evaluation of the cost of the machine duplication alternative.

Before proceeding simulation run, we should be sure that the steady state is established. Fig. 2 which is a plot realized by the "Output Analyser" depicts the transient behaviour of the simulation model after start-up from the "empty and idle" state. "Output Analyser" is a separate application that runs apart from Arena itself, but operates on output files created by the simulator Arena through the statistic data module. The system variable chosen to plot against time is the total work in process (TWIP) of all ten parts combined. The main attempt objective is to knowing how long the warm-up period should be. Fig. 2 shows the resulting plot of TWIP across the simulations, with the curves for several replication tests superimposed to mitigate the noise problem. From this plot, it seems clear that as far as the TWIP output is concerned, the run length of 25000 minutes is enough for the model to have settled out; rounding up a little to be conservative, we'll select 30000 minutes as our warm-up period.

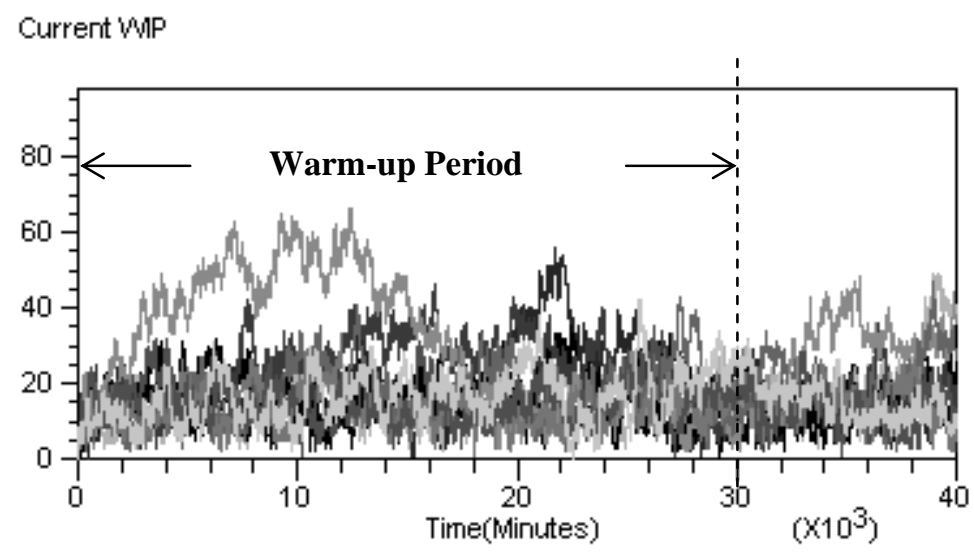

Figure 2: Within-run WIP plots for the investigated model.

Several simulation runs were made for the initial system configuration, each run for total parts demand (28800 batches). The results of these simulation runs that are realized with the help of the simulator ARENA were averaged. The result of these runs is shown in Table IV and in Table V.

Table IV: Results of simulation of machines for the initial model.

\begin{tabular}{|c|c|c|}
\hline Machines & $N W$ (batches) & $R U(\%)$ \\
\hline M1 & 0.35 & 54 \\
\hline M2 & 7.17 & 93 \\
\hline M3 & 0.10 & 25 \\
\hline M4 & 0.58 & 64 \\
\hline M5 & 0.03 & 30 \\
\hline M6 & 0.27 & 49 \\
\hline M7 & 1.26 & 74 \\
\hline M8 & 0.47 & 67 \\
\hline M9 & 0.24 & 52 \\
\hline
\end{tabular}


Table IV gives the experiment performance measures that are the average number of batches waiting in machine queue $(N W)$ and the machine utilization rate $(R U)$ for each machine. The result indicated that M2 is a potential bottleneck machine. Sure enough, it has a $R U$ nearly to one and a high $N W$ compared with the other machines. It has priority for machine duplication decision. Table $\mathrm{V}$ details the cost of transfer movement for each part $i$.

Table V: Results of simulation of parts of the initial model.

\begin{tabular}{|c|c|c|c|c|c|}
\hline Parts & $M T T_{i}(\mathrm{~min})$ & $M M T_{i}(\mathrm{~min})$ & $M W T_{i}(\mathrm{~min})$ & $M F T_{i}(\mathrm{~min})$ & $C T_{i}(\$)$ \\
\hline P1 & 63.61 & 90.90 & 195.11 & 349.63 & 17583 \\
\hline P2 & 21.33 & 56.00 & 178.37 & 255.70 & 11169 \\
\hline P3 & 0.00 & 20.45 & 171.71 & 192.16 & 0 \\
\hline P4 & 18.16 & 53.70 & 175.51 & 247.37 & 1407 \\
\hline P5 & 25.29 & 32.95 & 43.22 & 101.46 & 7693 \\
\hline P6 & 39.14 & 77.30 & 172.78 & 289.22 & 10969 \\
\hline P7 & 0.00 & 37.15 & 45.09 & 82.24 & 0 \\
\hline P8 & 23.00 & 60.35 & 59.42 & 142.77 & 8188 \\
\hline P9 & 0.00 & 46.85 & 15.75 & 62.60 & 0 \\
\hline P10 & 25.26 & 49.15 & 47.70 & 122.11 & 9137 \\
\hline Total & 215.80 & 512.80 & 1104.67 & 1845.27 & \\
\hline
\end{tabular}

It is important to design a common measure for many alternatives. We have selected to measure the cost-effectiveness of any EE-elimination alternative in terms of dollars invested per number of intercell transfers eliminated. In this way, one can compare all alternatives on an even basis.

Table VI: Summary of economical results.

\begin{tabular}{|c|c|c|c|}
\hline Exceptional parts & Initial $C T_{i}(\$)$ & $\begin{array}{c}\text { Necessary machine(s) } \\
\text { duplicated }\end{array}$ & Acquisition cost $\left(A C_{i}\right)$ \\
\hline $\mathrm{P} 1$ & 17583 & M4 and M6 in C1 & 20000 \\
\hline $\mathrm{P} 2$ & 11169 & M8 in C1 & 10000 \\
\hline P4 & 1407 & \multirow{2}{*}{ M2 in C2 } & \multirow{2}{*}{10000} \\
\hline P6 & 10969 & & \\
\hline P5 & 7693 & M7 in C2 & 10000 \\
\hline P8 & 8188 & M4 in C3 & 10000 \\
\hline P10 & 9137 & M1 in C3 & 10000 \\
\hline
\end{tabular}

In terms of parts 1, 5, 8 and 10, it was not economical to duplicate corresponding machines. Thus, while the acquisition cost of new equipment was higher than the total intercellular cost. For each part, the multiple intercellular moves required were cheaper than machine duplication. For parts 2, 4, and 6 the purchase of new machines M2 and M8 was justified. 
Table VII: Results for the improved system.

\begin{tabular}{|c|c|c|c|c|}
\hline Parts & $M T T_{i}(\min )$ & $M M T_{i}(\mathrm{~min})$ & $M W T_{i}(\mathrm{~min})$ & $M F T_{i}(\mathrm{~min})$ \\
\hline P1 & 64.44 & 90.90 & 40.62 & 195.96 \\
\hline P2 & 0.00 & 52.50 & 8.01 & 60.51 \\
\hline P3 & 0.00 & 20.45 & 14.16 & 34.61 \\
\hline P4 & 0.00 & 50.70 & 19.09 & 122.71 \\
\hline P5 & 25.90 & 32.95 & 43.03 & 69.79 \\
\hline P6 & 0.00 & 68.30 & 17.04 & 101.88 \\
\hline P7 & 0.00 & 37.15 & 47.54 & 85.34 \\
\hline P8 & 23.00 & 60.35 & 42.53 & 84.69 \\
\hline P9 & 0.00 & 46.85 & 15.77 & 125.88 \\
\hline P10 & 24.69 & 49.15 & 40.62 & 62.62 \\
\hline Total & 138.03 & 509.30 & 296.66 & 943.99 \\
\hline
\end{tabular}

After evaluation of the costs of inter-cellular movements, which permit the intercell transfers, we can now evaluate the effects of machines duplication. A modified simulation model was made and new simulations can be run in order to observe and to validate the acquisition of new machines M2 and M8. Tables VII and VIII detail results of the proposed improvement when using new machines M2 and M8. Comparing the results in Table V with that in Table VII, it is noted that the proposed machines acquisition has provided better performance measures. Sure enough, the MFT is enormously reduced: it passes from 1845.27 minutes to 943.99 minutes. The same observation is valid for the remainder performance measures and specially the mean waiting time. Table VII confirms that no intercellular transfers were eliminated for parts 1, 5, 8 and 10. Table VIII indicates that all machines have satisfactory performance measures ( $N W$ and $R U$ ).

Table VIII: Results of simulation of machines after duplication.

\begin{tabular}{|c|c|c|}
\hline Machines & $N W$ (batches) & $R U(\%)$ \\
\hline M1 & 0.36 & 0.55 \\
\hline M2 in C1 & 0.06 & 0.54 \\
\hline M2 in C2 & 0.05 & 0.34 \\
\hline M3 & 0.09 & 0.24 \\
\hline M4 & 0.56 & 0.64 \\
\hline M5 & 0.02 & 0.27 \\
\hline M6 & 0.27 & 0.49 \\
\hline M7 & 1.31 & 0.74 \\
\hline M8 in C3 & 0.01 & 0.43 \\
\hline M8 in C1 & 0.01 & 0.19 \\
\hline M9 & 0.26 & 0.53 \\
\hline
\end{tabular}

Note that, once economical results are estimated, the subcontracting cost as another alternative for eliminating the exceptional parts can be also evaluated and compared with the other alternatives. It is a viable alternative to the duplication of exceptional machines. We observe that in this problem there are substantial benefits gained from employing a mixed 
strategy as opposed to a pure strategy that employ universally machines duplication to eliminate EE. This procedure was ignored by previous approaches.

\section{CONCLUSION}

The paper presents a methodology-based simulation for evaluating the elimination of EE from CF solutions. The current method is designed to be used after the CF process is completed. It evaluates and compares two alternatives actions: an exceptional machine can be duplicated, or it may be permitted. Several production parameters are incorporated into the proposed simulation study such as part sequence; production batch size and setup time in evaluating the cost of various alternatives. It takes into consideration the stochastic aspect in the CM system. It results in a prioritized list of alternatives that indicates to the decision-makers which actions would be the most cost-effective. Such a list would be great value in those situations where EE tend to reduce the effectiveness of GT design. In addition, this paper demonstrates that the duplication of exceptional machines may not be the cost-effective alternative, like recommended by previous researches in the CF area.

However, due to the complex nature of this problem, the proposed method provides a first step in addressing a very important cell formation issue. Although the present methodology is applied to a specific three-cell model, it can be readily generated by an automatic simulation model generation. Other manufacturing information must be inserted in simulation model such as failures of machines, maintenance policies and production control strategy. Extending the proposed approach to this direction is our interesting research perspective.

\section{REFERENCES}

[1] Burbidge, J. L. (1992). Change to group technology: Process organization is obsolete, Int. J. of Production Research, Vol. 30, No. 5, 1209-1219

[2] Shambu, G. (1996). Performance evaluation of cellular manufacturing systems: a taxonomy and review of research, Int. J. of Operations \& Production Management, Vol. 8, 81-103

[3] Singh, N.; Rajamani, D. (1996). Cellular manufacturing systems: Design, Planning and control, Chapman \& Hall, New York

[4] King, J. R. (1980). Machine-component grouping in production flow analysis: an approach using a rank order clustering algorithm, Int. J. of Production Research, Vol. 18, 213-232

[5] Chan, H.; Milner, D. (1982). Direct clustering algorithm for group formation in cellular manufacturing, Journal of Manufacturing Systems, Vol. 1, No. 1, 65-67

[6] Hachicha, W.; Masmoudi, F.; Haddar, M. (2007). Formation of machine groups and part families in cellular manufacturing systems using a correlation analysis approach, Int. J. of Advanced Manufacturing Technology, accepted ( $4^{\text {th }}$ January 2007), doi:10.1007/s00170-007-0928-9

[7] Gupta, T.; Saifoddini, H. (1990). Production data based similarity coefficient for machinecomponent grouping decisions in the design of a cellular manufacturing system, Int. J. of Production Research, Vol. 28, 1247-1269

[8] Slim, H.; Askin, R.; Vakharia, A. J. (1998). Cell formation in Group technology: review, evaluation and directions for future research, Computers \& Industrial engineering, Vol. 34, 3-20

[9] Hachicha, W.; Masmoudi, F.; Haddar, M. (2006). A correlation analysis approach of cell formation in cellular manufacturing system with incorporated production data, Int. J. of Manufacturing Research, Vol. 1, No. 3, 332-353

[10] Sarker, B. R.; Balan, C. V. (1996). Cell formation with operation times of jobs for even distribution of workloads, Int. J. of Production Research, Vol. 34, No. 5, 1447-1468

[11] Shafer, S.; Kern, G.; Wei, J. C. (1992). A mathematical programming approach for dealing with exceptional elements in cellular manufacturing, Int. J. of Production Research, Vol. 30, 10291036 
[12] Wemmerlöv, U.; Hyer, N. L. (1986). The part family/machine group identification problem in cellular manufacturing, Journal of Operation Management, Vol. 6, 125-147

[13] McAuley, J. (1972). Machine grouping for efficient production, The Production Engineer, Vol. $56,451-454$

[14] King, J. R. (1980). Machine-component grouping in production flow analysis: an approach using a rank order clustering algorithm, Int. J. of Production Research, Vol. 18, 213-232

[15] Burbidge, J. L. (1975). The introduction of Group technology, Halster Press and John Wiley, New York

[16] Kusiak, A. (1987). The generalized group technology concept, Int. J. of Production Research, Vol. 25, 561-569

[17] Seifoddini, H. (1989). Duplication process in machines cells formation in group technology, IIE Transactions, Vol. 21, No. 4, 382-388

[18] Foulds, L. R.; French, A. P.; Wilson, J. M. (2006). The sustainable cell formation problem: manufacturing cell creation with machine modification costs, Computers \& Operations Research, Vol. 33, 1010-1032

[19] Cheng, C. H.; Goh, C. H.; Lee, A. (2001). Designing group technology manufacturing systems using heuristic branching rules, Computers \& Industrial engineering, Vol. 40, 117-131

[20] Kamrani, A.; Hubbard, K.; Parsaep, H.; Leew, H. R. (1998). Simulation-based methodology for machine cell design, Computers \& Industrial Engineering, Vol. 34, No. 1, 173-188

[21] Habchi, G.; Berchet, C. (2003). A model for manufacturing systems simulation with a control dimension, Simulation Modelling Practice and Theory, Vol. 11, 21-44

[22] Masmoudi, F. (2006). Sizing manufacturing cell machines based on the simulation and an expert system, Int. J. of Simulation Modelling, Vol. 5, No. 2, 45-55

[23] Faizul, H.; Douglas, A. H.; Zubair, M. M. (2001). A simulation analysis of factors influencing the flow time and through-put performances of functional and cellular layouts, Integrated Manufacturing Systems, Vol. 12, 285-295

[24] Burgess, A. G.; Morgan, I.; Vollmann, T. E. (1993). Cellular manufacturing: its impact on the total factory, Int. J. of Production Research, Vol. 31, 2059-2077

[25] Shambu, G.; Suresh, N. C. (2000). Performance of hybrid cellular manufacturing systems: A computer simulation investigation, European Journal of Operational Research, Vol. 120, 436458

[26] Polajnar, A.; Buchmeister, B.; Leber, M. (1995). Analysis of different transport solutions in the flexible manufacturing cell by using computer simulation, Int. J. of Operations and Production Management, Vol. 15, No. 6, 51-58

[27] Masmoudi, F.; Masmoudi, Y.; Maalej, Y. A. (2006). Optimization of product transfer with constraint in robotic cell using simulation, Int. J. of Simulation Modelling, Vol. 5, No. 3, 89-100

[28] Shafer, S. M.; Meredith, J. R. (1993). An empirically-based simulation study of functional versus cellular layouts with operations overlapping, Int. J. of Operations and Production Management, Vol. 13, 47-62

[29] Law, M.; Kelton, W. D. (2000). Simulation modeling and analysis, Mc Graw Hill, New York

[30] Selen, W. J.; Ashayeri, J. (2001). Manufacturing cell performance improvement: a simulation study, Robotics and Computer Integrated Manufacturing, Vol. 17, 169-176

[31] Kelton, W.D.; Sadowski, R. P.; Sadowski, D. A. (2002). Simulation with Arena, Mc Graw Hill, New York

[32] Arena Standard User's Guide (2002). Doc ID ARENAS-UM001C-EN-P, Rochwell Software Inc. 